\title{
Erratum to: Epidemiology of burn injuries in Nepal: a systemic review
}

Sanjib Tripathee and Surendra Jung Basnet ${ }^{*}$

\section{Erratum}

After the publication of this article [1] the editor noticed some erroneous ' $n$ ' values in the sub-headings of Table 2. The original article has been updated to omit these values. The correct updated version of the table is also shown below.

Received: 5 May 2017 Accepted: 9 May 2017

Published online: 24 May 2017

\section{Reference}

1. Sanjib T, Surendra Jung B. Epidemiology of burn injuries in Nepal: a systemic review. Burns \& Trauma. 2017;5:10. doi:10.1186/s41038-017-0075-y.

\footnotetext{
* Correspondence: surendrajungbasnet@hotmail.com

Plastic Surgery Department, Kirtipur Hospital, Kirtipur, Nepal
} 
Table 2 Mechanism of burn injury in Nepal

\begin{tabular}{|c|c|c|c|c|c|c|c|c|}
\hline Study & Age group & $\begin{array}{l}\text { Total patient } \\
\text { number, } \mathrm{n}\end{array}$ & $\begin{array}{l}\text { Flame burn } \\
(\%)\end{array}$ & $\begin{array}{l}\text { Scald burn } \\
(\%)\end{array}$ & $\begin{array}{l}\text { Electric burn } \\
(\%)\end{array}$ & $\begin{array}{l}\text { Contact burn } \\
(\%)\end{array}$ & $\begin{array}{l}\text { Chemical burn } \\
(\%)\end{array}$ & $\begin{array}{l}\text { Others } \\
(\%)\end{array}$ \\
\hline Liu et al. [5] & All ages & 237 & $152(64.1)$ & $67(28.3)$ & $9(3.8)$ & $1(0.4)$ & $3(1.3)$ & $5(2.1)$ \\
\hline Shrestha et al. [8] & Pediatrics & 22 & $10(45.4)$ & $12(54.5)$ & - & - & - & - \\
\hline Poudel-Tandukar et al. [9] & Pediatrics & 350 & 125(35.7) & 187(53.4) & - & $36(10.3)$ & - & $2(0.6)$ \\
\hline Chalise et al. [10] & All ages & 50 & $33(66.0)$ & $8(16.0)$ & $7(14.0)$ & - & $2(4.0)$ & - \\
\hline Dahal et al. [6] & All ages & 100 & $64(64.0)$ & $21(21.0)$ & 14(14.0) & - & $1(1.0)$ & - \\
\hline Rai et al. [11] & All ages & 78 & $48(61.5)$ & $15(19.2)$ & $11(14.1)$ & - & - & $4(5.1)$ \\
\hline Gupta et al. [29] & All ages & 54 & 21(38.9) & $32(59.3)$ & - & - & - & $1(1.9)$ \\
\hline Sharma et al. [7] & All ages & 819 & $633(77.3)$ & $69(8.4)$ & $104(12.7)$ & $2(0.2)$ & $5(0.6)$ & $6(0.7)$ \\
\hline
\end{tabular}

